\title{
The impact of inlet boundary layer thickness on the unsteady aerodynamics of S-duct intakes
}

\author{
Matteo Migliorini ${ }^{*}$, Pavlos K. Zachos ${ }^{\dagger}$ and David G. MacManus ${ }^{\ddagger}$ \\ Propulsion Engineering Centre, School of Aerospace Transport and Manufacturing, \\ Cranfield University, MK43 OAL, Cranfield, UK
}

\begin{abstract}
The need to reduce aero-engine emissions and direct operating costs is driving the civil aerospace sector towards considering more integrated propulsion systems. Many of the proposed novel aircraft architectures employ convoluted intakes for either the aero-engine or propulsion system. These intakes are characterized by unsteady distortion that can hinder the performance and operability of the propulsion system. This work assesses the impact of the inlet boundary layer on the unsteady aerodynamics of an S-duct intake using time-resolved particle image velocimetry at the aerodynamic interface plane. An increase in the boundary layer thickness at the intake inlet increases the flow unsteadiness on the swirl angle by up to 40\% relative to the baseline case. The azimuthal orientation of the inlet boundary layer modifies the intensity and topology of the most frequent swirl distortion pattern. For a relatively thick inlet boundary layer, the reduction of the dominant frequencies associated with the unsteady swirl angle is postulated to be beneficial for the engine stability. Overall, this works gives guidelines for the integration between the intake and the engine across the range of potential inlet operating conditions.
\end{abstract}

\section{Nomenclature}

AIP $=$ aerodynamic interface plane

$A_{\text {closed }}=$ area covered by the honeycomb mesh, $\mathrm{mm}^{2}$

$A_{\text {total }}=$ area of the $\mathrm{S}$-duct inlet section, $\mathrm{mm}^{2}$

$B L I=$ Boundary Layer Ingestion

$D_{i n} \quad=$ S-duct inlet plane diameter, $\mathrm{mm}$

$D_{\text {out }} \quad=$ S-duct outlet plane diameter, $\mathrm{mm}$

$\mathrm{H} \quad=$ S-duct vertical offset

$\mathrm{K}=$ screen loss coefficient, $\left(p_{01}-p_{02}\right) / q_{2}$

$\mathrm{L} \quad=\quad$ S-duct length

$\mathrm{M} \quad=$ Mach number

$p_{0} \quad=$ total pressure, $\mathrm{Pa}$

$q \quad=$ dynamic pressure, $\mathrm{Pa}$

$\mathrm{Re} \quad=$ Reynolds number

$\mathrm{SD}=$ swirl directivity distortion descriptor

SI $\quad=$ swirl intensity distortion descriptor, ${ }^{\circ}$

SP $\quad=$ swirl pairs distortion descriptor

St $\quad=$ Strouhal number, $f D_{\text {out }} /\langle\bar{w}\rangle$

\footnotetext{
${ }^{*}$ PhD Student, Propulsion Engineering Centre, Member AIAA.

${ }^{\dagger}$ Lecturer, Propulsion Engineering Centre, Member AIAA.

* Professor, Propulsion Engineering Centre, Member AIAA.
} 


$\begin{array}{ll}\text { std } & =\text { standard deviation } \\ v_{\theta} & =\text { circumferential velocity component, } \mathrm{m} / \mathrm{s} \\ w & =\text { out-of-plane velocity component, } \mathrm{m} / \mathrm{s} \\ \alpha & =\text { swirl angle, }{ }^{\circ}, \tan ^{-1}\left(v_{\theta} / w\right) \\ \delta & =\text { boundary layer thickness, mm } \\ \theta & =\text { azimuthal orientation of the inlet boundary layer, }{ }^{\circ} \\ \langle\rangle & =\text { time average } \\ - & =\text { area average }\end{array}$

\section{Introduction}

Aero-engine designers are seeking innovative ways to improve the efficiency of the propulsion system towards reduced operating costs [1], fuel consumption, weight and exhaust gas emissions [2]. Novel aircraft solutions propose a closer integration between the propulsion system and aircraft fuselage, with some of these configurations also expecting benefits from Boundary Layer Ingestion (BLI), reduced frontal area and reduced wakes [3] which can lead to overall system improvements. Aircraft configurations with closely-coupled airframe and propulsion systems have been proposed, such as NASA Aurora D8 [4] and ONERA NOVA [5]. Feasibility studies conducted on these concepts, both numerically and experimentally [6,7], showed a potential reduction in fuel burn up to $14 \%$ in comparison with conventional ultra-high bypass baseline turbofan configurations [6]. However, the use of convoluted aero-engine intakes is known to generate complex unsteady distortions [8] that can be detrimental for the propulsion system performance, promote fan stall, reduce the compressor surge margin [9] and cause mechanical compatibility issues due to forced excitation [10-12]. For some particular designs, the aeromechanical analysis highlighted the need to modify the compressor fan geometry to be flutter-free at design conditions [13]. In other cases, the inlet velocity nonuniformity was found to produce uneven radial pressure loading on the fan and to promote three-dimensional dynamic stall [14]. In addition, the variability of an aircraft operating condition in terms of pitch and yaw angles, can cause a notable change of the flow field upstream of the convoluted intake, which in turn can affect the unsteady flow distortion at the Aerodynamic Interface Plane (AIP) [15]. An understanding of the unsteady distortion characteristics across the range of potential aircraft operating conditions is therefore a key element for the design and integration of the intake with the airframe. The use of devices to synthetically generate total pressure distortion and vortices at the intake inlet is an established approach [16]. The review of different design methods and analytical solutions can be found in both Pinker and Herbert [17], and Laws and Livesey works [18]. More recently, 3D printing techniques have been used for the generation of pressure profiles, to simulate the operation of the intake with a thick boundary layer profile [19]. Methods with CFD and experimental calibrations showed the possibility to reproduce swirl patterns [20], generalized pressure distortions [21] and combined pressure and swirl distortion [22]. There is little previous work on the effect of the different inlet boundary layer heights to the unsteady flow distortion at the aerodynamic interface plane of an S-duct intake. Few published research assessed the flow distortion for intakes under yaw and pitch angles [15]. Previous studies [23-25] used Time-Resolved Particle Image Velocimetry (TR-PIV) to measure the unsteady flow distortion characteristics at the exit plane of S-shaped aero-engine intakes. This non-intrusive experimental technique enables synchronous measurement of the 3-component velocity vector across a plane with spatial resolution up to two orders of magnitude higher than standard intrusive distortion measurement techniques [25]. In this current work, TR-PIV was used to assess the effect of non-uniform inlet conditions on the unsteady distortion characteristics at the exit plane of an S-duct intake. The effect of the inlet boundary layer thickness and orientation were also investigated.

\section{Methods}

\section{A. Experimental facility and operating conditions}

The S-duct intake test facility at Cranfield University was used for the tests. A detailed description is provided by Zachos et al. [25]. The layout of the test facility is shown in Fig. 1. The airflow is drawn from the seeding chamber through a bell mouth aperture (Fig. 1) and it is straightened in the conditioning section. At station 3, honeycomb screens can be placed to create boundary-layer type pressure profiles. Different S-duct geometry can be installed in the rig at station 5. The selected S-duct geometry is a diffusing duct similar to the configuration also investigated by Garnier et al. [26]. It has an inlet diameter $D_{\text {in }}=121.6 \mathrm{~mm}$ and an area ratio $A_{\text {in }} / A_{\text {out }}=1.52$. The $\mathrm{S}$-shape features a 
vertical offset $H / D_{\text {in }}=2.44$ and an aspect ratio $L / D_{\text {in }}=0.495$. Downstream of the S-duct, a transparent section provides optical access for the Particle Image Velocimetry (PIV) measurements. The Aerodynamic Interface Plane at which the measurements are taken is placed at $0.41 D_{\text {out }}$ downstream of the S-duct exit (Fig. 1-6). The operating point of the rig is set at Mach $0.27\left(R e_{D_{\text {in }}}=7.38 \times 105\right)$ at the reference plane which is $1.45 D_{\text {in }}$ upstream of the S-duct inlet (Fig. 1-4). At this operating point, the reference boundary layer thickness at this plane is approximately $\delta / D_{i n}=0.04$.

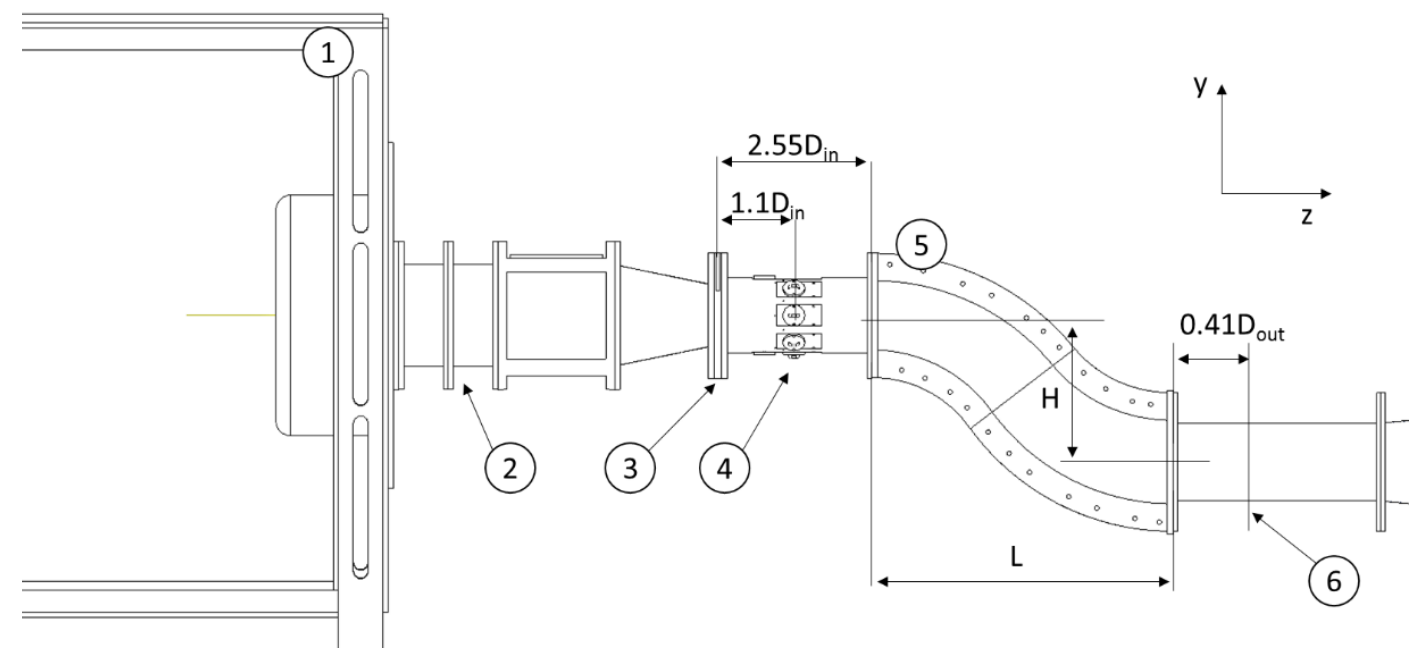

Fig. 1: Cranfield test facility schematic: 1- seeding chamber, 2- flow conditioning section, 3- honeycomb screen section, 4- pressure measurements ports, 5- S-duct, 6- measurement plane (AIP).

\section{B. Time-Resolved Stereo Particle Image Velocimetry}

Time-resolved Stereo Particle image Velocimetry (TR-PIV) was used to acquire velocity fields at an Aerodynamic Interface Plane (AIP) which is located $0.41 D_{\text {out }}$ downstream the S-duct exit plane. The flow has been seeded with DiEthyl-Hexyl Sebacate particles of approximately $1 \mu \mathrm{m}$ via a Laskin nozzle particle generator. The particles are illuminated with a dual cavity pulsed Nd:YAG laser at the AIP. The cameras were placed in a stereo configuration at the AIP. They featured a 1MP CMOS sensor with a resolution of 1280 x $800 \mathrm{px}$ and a maximum straddle rate of $16,600 \mathrm{fps}$. They were equipped with a pair of 1.8/D Nikkor lenses with a focal length of $60 \mathrm{~mm}$. The calibration of the cameras was achieved with a single-plane calibration target that was traversed axially. The temporal resolution of the TR-PIV acquired velocity fields was set at $4 \mathrm{kHz}$, which is 10 times the highest dominant flow frequency $(\mathrm{St}=$ 1.06) [27]. A dataset of 20,000 instantaneous flow fields was acquired for the statistical convergence of the results [28]. They were processed with a direct correlation method and a recursive multi-pass window approach with decreasing window size from $128 \mathrm{px}^{2}$ to $32 \mathrm{px}^{2}$. The achieved spatial resolution of the velocity fields was approximately $0.0153 D_{\text {out }}\left(2.3 \mathrm{~mm}^{2}\right)$ in both directions across the AIP. Only the data within $90 \%$ of the AIP radius has been used for the analysis, in order to remove the effect of spurious vectors near the domain boundaries due to laser light reflections. The total number of velocity vectors across the AIP is approximately 2,900. An uncertainty estimate [29] for the three-dimensional, reconstructed velocity vector was $2.6 \%$ of the area-averaged, time-averaged out-of-plane velocity at the AIP. The uncertainty on swirl angle is approximately $1.4^{\circ}$.

\section{Inlet total pressure profiles}

Berrier et al. [30] assessed the possible geometries for blended-wing-body designs with extensive wind tunnel testing. Giuliani et al. [14] showed that the compressor could stall because of the unsteady flow distortion. Following on from the work of Giuliani, this current study quantifies the characteristics of the unsteady swirl and velocity distortion for S-duct intakes with a non-uniform pressure distribution at the inlet. Recent studies demonstrated the use of devices to impose non-uniform inlet conditions, including swirl [30], boundary layers [19] and, more generally, total pressure distortion screens [21] for the application in model-scale research engine testing. In this work, 3Dprinted honeycomb screens are used to generate a boundary layer at the of S-duct inlet. The selected boundary layers are characterized by a different thickness at the bottom dead center. Profile A (Fig. 2a) was defined based on previous work of Giuliani et al. [14] as a typical flow profile upstream of a boundary layer ingesting propulsion system with a non-dimensional thickness of $\delta /$ Din $=0.332$ at the bottom dead center. A second inlet flow profile, Profile $B$, with a 
non-dimensional $\delta /$ Din $=0.572$ was also assessed as part of the current study (Fig. $2 b$ ). Both of these inlet profiles are thicker than the reference inlet boundary layer $(\delta / \operatorname{Din}=0.04)$. The profiles were also rotated azimuthally by $45^{\circ}$ and $90^{\circ}$ to represent the operation of the intake under high angles of pitch and yaw [15]. The total pressure measurements were acquired with a sample rate of $500 \mathrm{~Hz}$ for $12 \mathrm{~s}$ and had overall uncertainty of $0.06 \%$.

The screens have a variable porosity across the vertical direction to generate the required total pressure profiles. The gauze designs were based on the specification of loss coefficient distribution across the plane. The local pressure loss coefficient at each point across the plane of the distortion gauze was expressed as:

$$
K=\frac{p_{01}-p_{02}}{q_{2}}
$$

Where $p_{01}-p_{02}$ is the total pressure drop across the screen while $q_{2}=\frac{1}{2} \rho V_{2}^{2}$ is the downstream dynamic head [19]. To determine the required total pressure loss coefficient distribution for each target flow profile, a database of constant solidity screens was used whose total pressure loss coefficients were measured experimentally. The variable porosity gauzes were designed using the database of constant solidity screens to define the required total pressure loss distribution for each target flow profile.
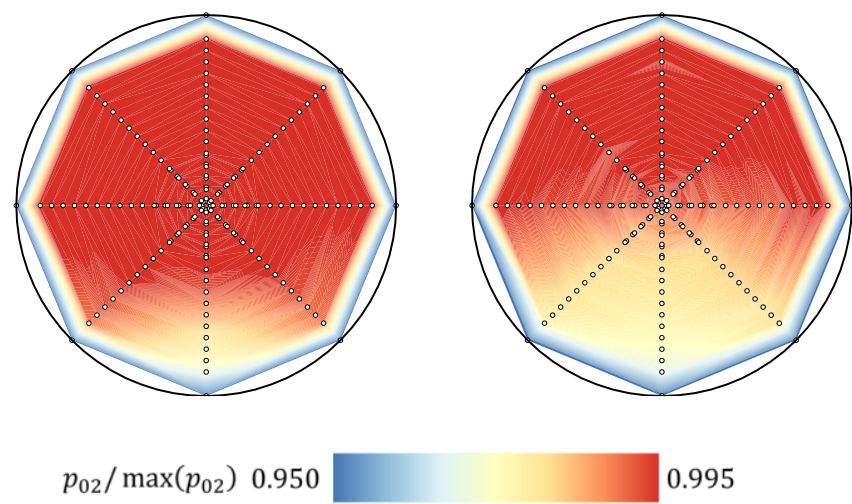

$$
p_{02} / \max \left(p_{02}\right) 0.950
$$

a) b)

Fig. 2: (a) Profile A and (b) Profile B total pressure distributions at the S-duct inlet.

\section{Swirl distortion descriptors}

The evaluation of the flow distortion was conducted using the distortion descriptors defined by the Society of the Automotive Engineers [31]. In this framework, swirl distortion is assessed using swirl descriptors that are evaluated on an offset of circumferential rings at the AIP. The swirl descriptors were evaluated along 72 equally spaced circumferential points for each ring, with a resolution of $5^{\circ}$. The rings are placed in 5 different radial positions so that they describe equal area circular sectors. The definitions of the descriptors and a sample twice-per revolution pattern are shown in Fig. 3. The swirl angle is assumed positive in the counter clockwise direction when the AIP is considered from downstream. Positive and negative circumferential extents, $\theta_{i, k}^{+}$and $\theta_{i, k}^{-}$define the size of the k-th swirling region in the i-th ring (Eq. 6). Positive and negative sector swirls $S S_{i, k}^{+}$and $S S_{i, k}^{-}$are defined as the mean swirl-angle value in each of the $\mathrm{m}$ swirling regions (Eq. 5).

$$
\begin{gathered}
S I(i)=\frac{\sum_{k=1}^{m} S S_{i, k}^{+} \cdot \theta_{i, k}^{+}+\sum_{k=1}^{m}\left|S S_{i, k}^{-}\right| \cdot \theta_{i, k}^{-}}{360} \\
S D(i)=\frac{\sum_{k=1}^{m} S S_{i, k}^{+} \cdot \theta_{i, k}^{+}+\sum_{k=1}^{m} S S_{i, k}^{-} \cdot \theta_{i, k}^{-}}{\sum_{k=1}^{m} S S_{i, k}^{+} \cdot \theta_{i, k}^{+}+\sum_{k=1}^{m}\left|S S_{i, k}^{-}\right| \cdot \theta_{i, k}^{-}} \\
S P(i)=\frac{\sum_{k=1}^{m} S S_{i, k}^{+} \cdot \theta_{i, k}^{+}+\sum_{k=1}^{m}\left|S S_{i, k}^{-}\right| \cdot \theta_{i, k}^{-}}{2 \cdot \operatorname{Max}\left\{S S_{i, k}^{+} \cdot \theta_{i, k}^{+}\left|S S_{i, k}^{-} \cdot \theta_{i, k}^{-}\right|\right\}_{k=1, \ldots m}}
\end{gathered}
$$




$$
\begin{gathered}
\alpha_{1}(i)=\operatorname{Max}\left\{S S_{i, k}^{+},\left|S S_{i, k}^{-}\right|\right\}_{k=1, \ldots, m} \\
\theta_{1}(i)=\theta_{i, L} \text { where }\left|S S_{i, L}\right|=\alpha_{1}(i)
\end{gathered}
$$

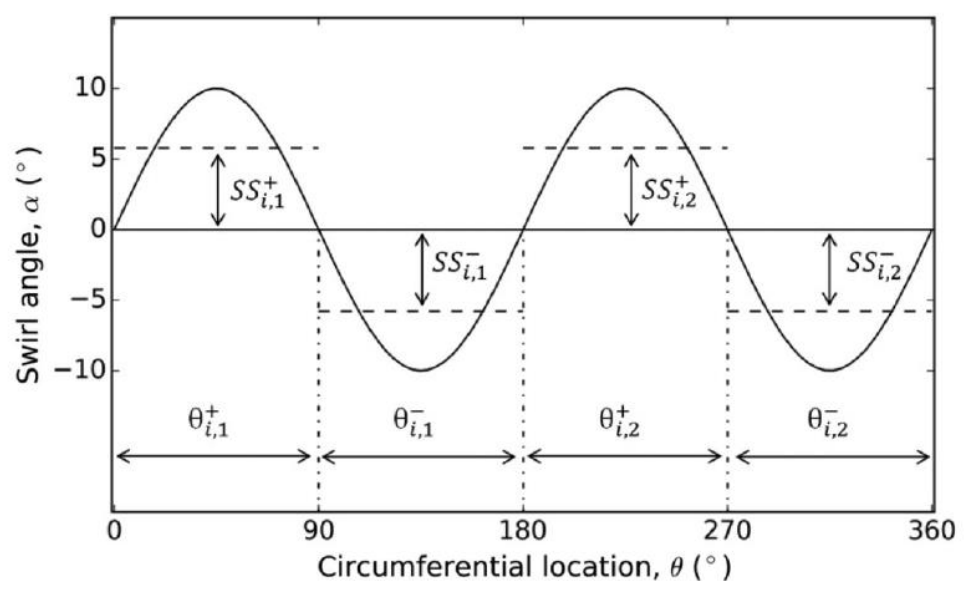

Fig. 3: Twice-per-revolution swirl distortion pattern [31].

The swirl descriptors were used to determine key characteristics of the unsteady distortion topologies. The swirl intensity (SI, Eq. 2) quantifies the averaged absolute swirl angle in each radial ring. The swirl directivity (SD, Eq. 3) depicts the overall sense of rotation of the swirling flow. The swirl pair (SP, Eq. 4) indicates the number of swirl patterns within the distribution. The TR-SPIV data is interpolated at these locations using the Delaunay triangulation method [32]. The representation of different swirl patterns is shown in Fig. 4 for different combinations of SP and SD values. The range, the trend and the frequency of the SP and SD descriptors can also be assessed with the joint Probability Density Functions (j-PDF) previously reported by Gil-Prieto et al. [28]. To compute the j-PDF, each descriptor has been discretized in 60 equi-spaced partitions. The probability of detection for the distortion patterns in a specific region of the j-PDF map is obtained by integration of the PDF over the desired area (Eq. 7). The resolution is approximately 0.03 for SP and SD.

$$
P\left(S D_{A} \leq S D \leq S D_{B}, S P_{A} \leq S P \leq S P_{B}\right)=\int_{S P_{A}}^{S P_{B}} \int_{S D_{A}}^{S D_{B}} P D F d S D d S P
$$

The spectral analysis was performed with an average periodogram method [33]. The datasets have been split in 20 segments of 1000 snapshots with a Hann window to reduce frequency leakage. The maximum frequency that is possible to identify is about $S t=5.0$, with a frequency resolution of $\Delta S t=0.01$ approximately. The contribution to the overall variance from different frequency bands has been calculated across the AIP to identify which are the frequency bands with the highest contributions. Each contribution is normalized by the overall area-averaged value of the variance across each frequency band. 


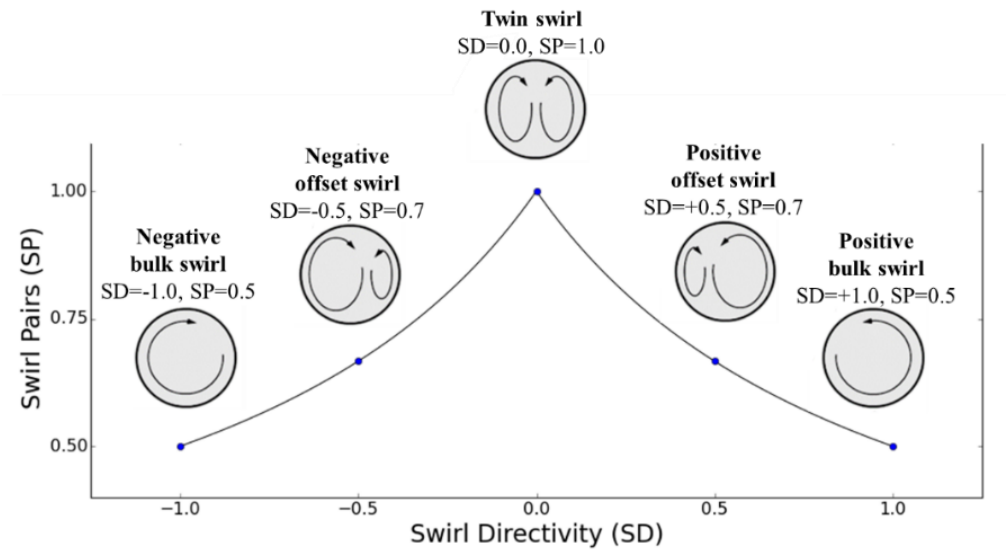

Fig. 4: Swirl topology for different combination of swirl pairs and directivity values [31].

\section{Results}

\section{A. Flow distortion unsteadiness}

Time-averaged and unsteady velocity distributions at the AIP for the two non-uniform inlet profile distributions (Profile A and B) are shown in Fig. 5 along with the baseline flow fields measured with an inlet flow profile with $\delta /$ Din $=0.04$. The time-averaged, non-dimensional out-of-plane velocity field (Fig. 5a) shows the two typical areas of high and low momentum in the upper and lower part of the AIP respectively. The characteristic shape and the magnitude of this velocity component is comparable with previous assessments $[27,23,25]$. The highest fluctuations of the out-of-plane velocity $\left(\overline{\langle w\rangle} / W_{\text {ref }}\right)$ is located in the center of the AIP with a peak value of about $20 \%$ of the areaaveraged out-of-plane velocity. The time-averaged swirl angle distribution $(\overline{\langle\alpha\rangle}$, Fig. 5c) shows the typical contrarotating twin swirl pattern that develop across the lower half of the measurement plane and it is associated with the development of the classical secondary flows for curved ducts [34]. The maximum values of the time-averaged swirl angle are in the range of $\pm 8^{\circ}$ and are located in bottom half of the section, at the duct boundaries. The highest levels of swirl angle unsteadiness $(s t d(\alpha))$ are located in the middle and lower half of the section with values up to $\operatorname{std}(\alpha)$ $=14^{\circ}$ approximately (Fig. 5d). Although the non-uniform inlet flow profiles $(\mathrm{A}, \delta / \operatorname{Din}=0.332$ and $\mathrm{B}, \delta / \mathrm{Din}=0.572)$ intensify the peak events and the unsteadiness of the flow field at the AIP, the overall flow topology of the out-ofplane velocity $\overline{\langle w\rangle}$ and of the swirl angle distributions remains unaltered in comparison to the uniform inlet condition $(\delta /$ Din $=0.04)$. For profile A $(\delta /$ Din $=0.332)$, given the fixed operating condition of $M=0.27$, the peak out-of-plane velocity (Fig. 5e) increased by $12 \%$ in the high momentum area and decreased by $18 \%$ in the low-momentum area in comparison to the reference case (Fig. 5a). The peaks of the unsteadiness distributions of the out of plane velocity $(\operatorname{std}(\alpha))$ (Fig. 5f) located at the middle and upper section increased by $17 \%$. The range of the time-averaged swirl angles increased from $\pm 8^{\circ}$ ( $\delta /$ Din $=0.04$, Fig. $\left.5 \mathrm{c}\right)$ to $\pm 13^{\circ}(\delta /$ Din $=0.332$, Fig. $5 \mathrm{~g}$ ) and its peak unsteadiness (Fig. 5l) increased from $14^{\circ}$ to $17^{\circ}$ approximately in comparison to the reference case (Fig. 5d). For the configuration with the thickest inlet boundary layer $(\delta / \operatorname{Din}=0.572)$, a higher level of distortion is noticeable. The peak unsteadiness of the out-of-plane component (Fig. 5j) increases from $\overline{\langle w\rangle} / W_{\text {ref }}=0.20$ to 0.25 . The time-averaged swirl angle range also increased in comparison to the reference case from \pm 8 (Fig. 5c) to $\pm 16^{\circ}$ (Fig. 5k). The fluctuating component of the swirl angle $\left(\operatorname{std}(\alpha)\right.$, Fig. 5l) increased to $19^{\circ}$ relative to the $14^{\circ}$ for the baseline configuration $(\delta / \mathrm{Din}=0.04)$ (Fig. $5 \mathrm{~d})$. The changes in the unsteadiness level of out-of-plane velocity $\overline{\langle w\rangle}$ and of the swirl angle $\overline{\langle\alpha\rangle}$ can be attributed to the strengthening of the secondary flows. The total pressure gradient of the thick boundary layers at the inlet of the Sduct promotes an early flow separation after the first bend. The mass flow non-uniformity at the inlet accentuates the roll up of the Dean vortices [34] and the downward pitching flow that moves from the top to the bottom of the S-duct cross-sections. 


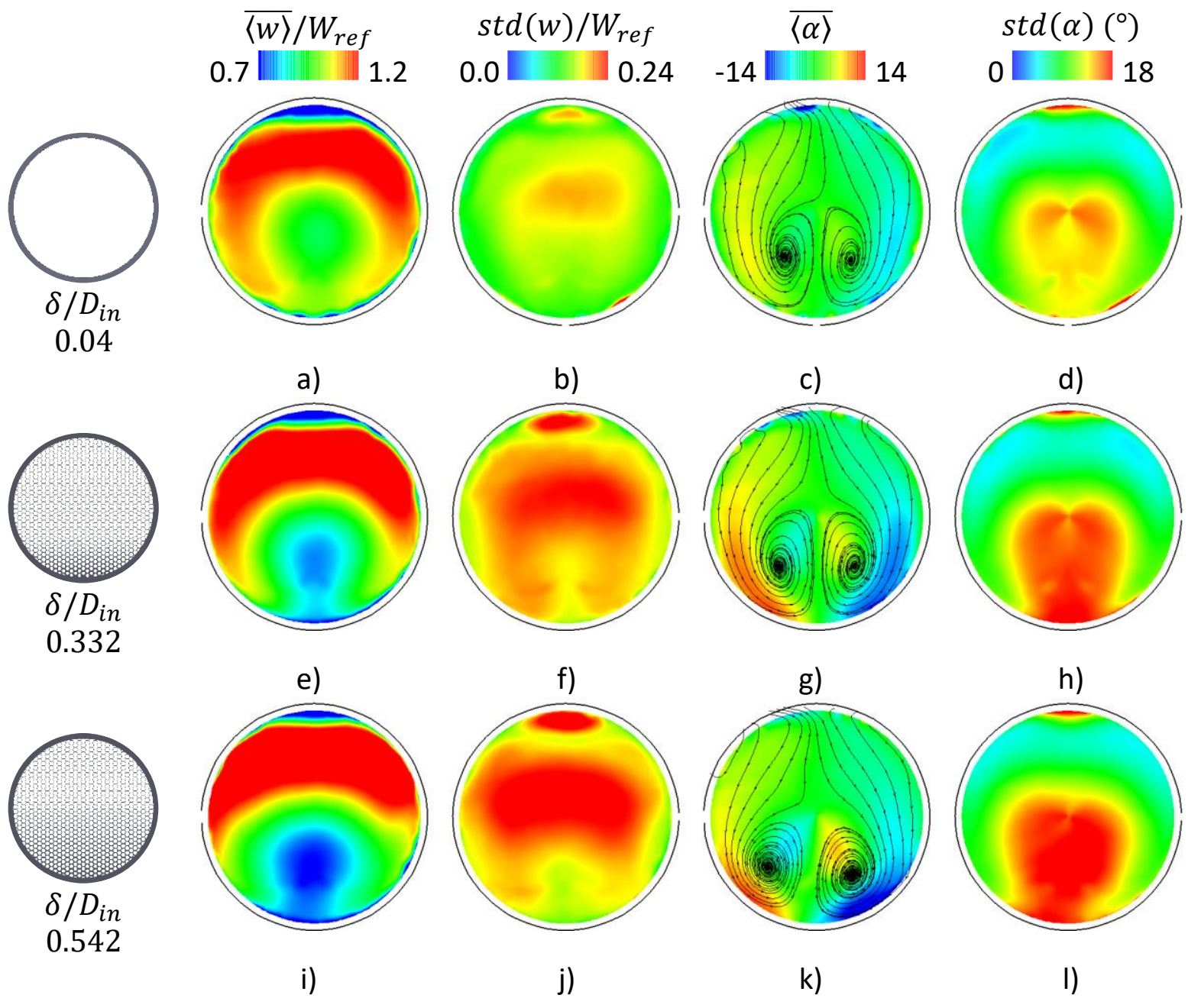

Fig. 5: Effect of inlet Profile $A\left(\delta / D_{\text {in }}=0.332\right)$ and Profile $B\left(\delta / D_{\text {in }}=0.572\right)$ on time-averaged and unsteady velocity and swirl angle distributions.

\section{B. The effect of inlet total pressure orientation}

To represent inlet conditions that are similar to the ones reported in previous assessments [15] for the operation of an intake under angles of pitch and yaw, the azimuthal orientation of the inlet flow Profile A $(\delta /$ Din $=0.332)$ and Profile $B(\delta / \operatorname{Din}=0.572)$ were varied starting from the high pressure loss region at bottom dead center $\left(\theta=0^{\circ}\right)$ to angles of $\theta=45^{\circ}, 90^{\circ}$ (Fig. 6). For the case where the inlet boundary layer is increased in thickness and centrally located at $\theta=0^{\circ}$, the previous results indicate that this increase in inlet vorticity generally augments the secondary flows within the duct. However, for configurations where the inlet vorticity is not aligned with the duct centerline $\left(\theta=45^{\circ}, 90^{\circ}\right)$ it is envisaged that the augmentation of the secondary flows will be biased in one orientation. Consequently, the associated secondary flow vortex gains strength and becomes predominant (Fig. 7c, g, k) and the low momentum region shifts towards a central-left position (Fig. 7e, i).

For Profile A $(\delta / \operatorname{Din}=0.332)$ at $\theta=45^{\circ}$, the peak out-of-plane velocity unsteadiness increases slightly to $\operatorname{std}(w) / W_{\text {ref }}=0.27$ (Fig. 7f) relative to 0.25 for the baseline orientation $\theta=0^{\circ}$. However, as $\theta$ is further increased 
to $90^{\circ}$ this unsteadiness reduces more notably to 0.20 (Fig. 7j). There is a more significant impact of the effect of $\theta$ on the average and unsteady swirl distortion. For example, the time-average maximum swirl angle increases from $10.5^{\circ}$ for $\theta=0^{\circ}$ to $17.2^{\circ}$ and $17.5^{\circ}$, as the inlet total pressure profile rotates to $\theta=45^{\circ}$ and $90^{\circ}$, respectively (Fig. $7 \mathrm{c}$, $\mathrm{g}, \mathrm{k})$. In contrast, as $\theta$ increases and the secondary flow becomes more asymmetric and dominated by one of the vortices, the unsteadiness in the swirl distortion reduces. Across the range of $\theta=0^{\circ}, 45^{\circ}, 90^{\circ}$ the maximum of the swirl unsteadiness $(\operatorname{std}(\alpha))$ reduces significantly from $17.0^{\circ}$ to $13.2^{\circ}$ (Fig. $\left.7 \mathrm{~d}, 1\right)$. Overall, for this inlet Profile A $(\delta /$ Din $=0.332)$ the effect of changing the azimuthal location of the inlet total pressure deficit is that there is a notable increase in the time averaged maximum swirl distortion, but there is a significant reduction in the swirl unsteadiness. As well as enhancing the vorticity that is biased to one side, the growth of the left vortex is also partially attributed to the effect of the asymmetry on the separated centerline shear layer. As the separation is also biased to one side, there is an additional downward pitching of the separated center flow which further strengthens the dominant vortex.

For Profile B with the thicker boundary layer $(\delta / \mathrm{Din}=0.572)$, the effect of the azimuthal orientation on the AIP flow distortion is broadly similar to that of Profile A, although with greater relative changes. Similar to Profile A, there are modest changes to the unsteadiness of the out-of-plane velocity, which varies from 0.26 to 0.28 to 0.24 for $\theta=0^{\circ}, 45^{\circ}, 90^{\circ}$, respectively. The effect of $\theta$ has a more notable impact on the swirl flow distortion. With Profile $\mathrm{B}$, as the inlet profile enhances the secondary flow of one of the primary vortices, the maximum time average swirl angle increases monotonically as $11.4^{\circ}, 21.1^{\circ}, 23.8^{\circ}$ for $\theta=0^{\circ}, 45^{\circ}, 90^{\circ}$, respectively. As with Profile A, although the timeaverage swirl distortion increased, the bias of the flow field results in a more stable condition and the unsteadiness of the swirl angle reduces. The swirl unsteadiness $(\operatorname{std}(\alpha))$ reduces from $19.8^{\circ}$ for $\theta=0^{\circ}$ to $16.7^{\circ}$ and $14.3^{\circ}$, as the inlet total pressure Profile B rotates to $\theta=45^{\circ}$ and $90^{\circ}$, respectively.

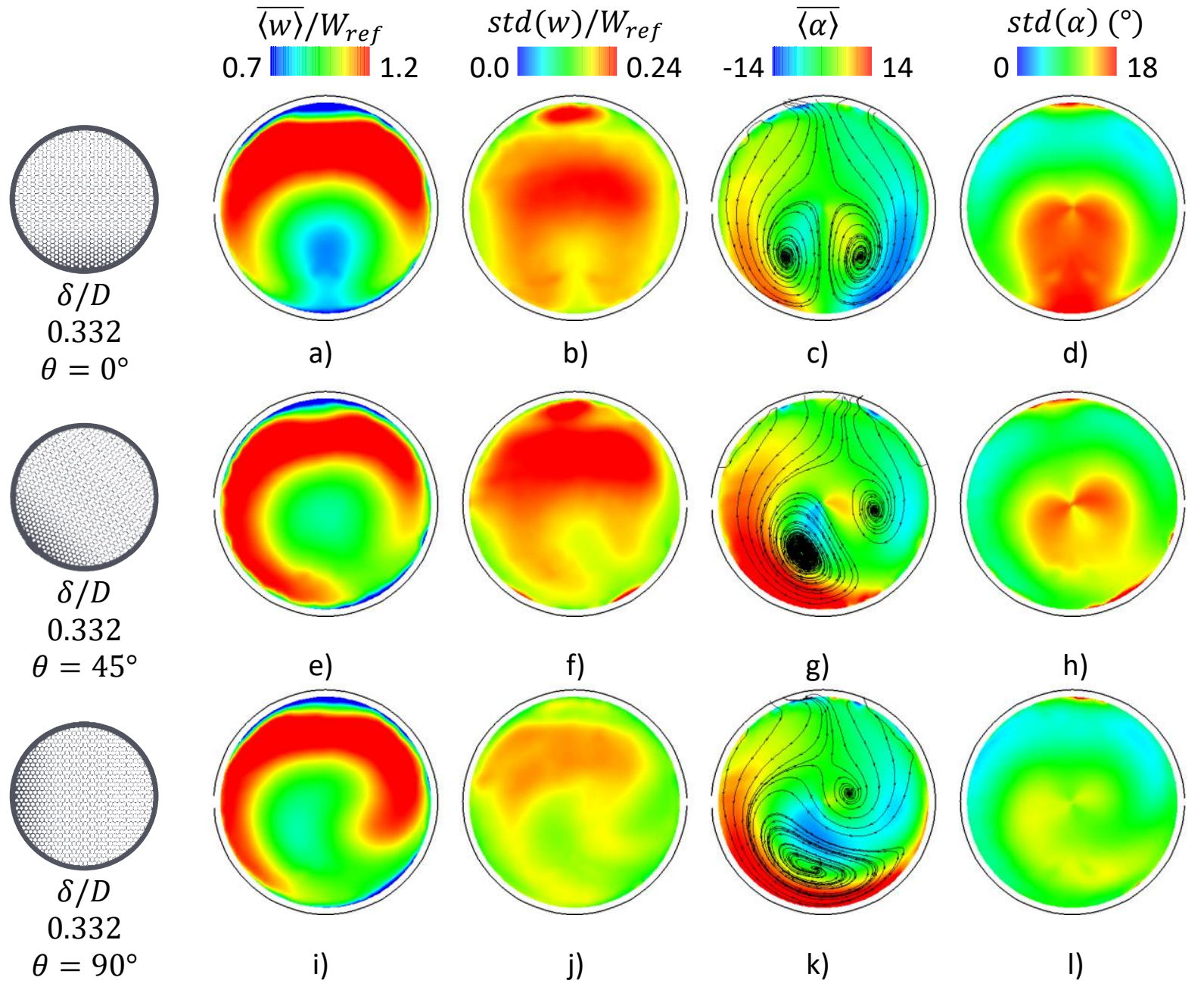

Fig. 7: Effect of inlet profile $A\left(\delta / D_{\text {in }}=0.332\right)$ and azimuthal orientation on time-averaged and unsteady velocity and swirl angle distributions. 


\section{Swirl distortion descriptors}

The flow distortion at the AIP can be characterized in terms of the swirl distortion metrics such as Swirl Intensity (SI), Swirl Pairs (SP) and Swirl Directivity (SD) [31]. For the baseline configuration ( $\delta /$ Din $=0.04)$, the SP-SD j-PDF distribution shows three high probability areas associated with events with twin, bulk positive and bulk negative swirl (Fig. 8e). The behavior is also evident in the SI-SP j-PDF distributions, which shows notable oscillations in the intensity of the swirl events and a high-probability band that ranges between $5^{\circ}-8.5^{\circ}$ SI and between bulk - twin swirl pattern. As reported by Gil-Prieto et al. [28], this SP-SD signature is associated with the dominant unsteady switching mode, which causes the oscillation between the various swirl patterns. This mode is associated with the unsteady changes in the flow from being bulk positive swirl, to twin swirl and to bulk negative swirl. These were identified also with DDES simulations by MacManus et al. [35] and Gil-Prieto and al. [27]. The unsteady S-duct flow field also exhibits a vertical mode which is associated with a modulation of the vertical extent of the low streamwise velocity region around its mean position.

The increase of the inlet boundary layer thickness from $\delta / \operatorname{Din}=0.04$ to $\delta / \operatorname{Din}=0.332$ (Profile A, $\theta=0^{\circ}$, Fig. $8 \mathrm{~b}$ ) shows that the most probable events are associated with an increase in the SI distortion metric from $7^{\circ}$ to $9.5^{\circ}$ approximately (Fig. 8a, b). In addition, the peak swirl events increase from SI $=14.5^{\circ}(\delta / \mathrm{Din}=0.04$, Fig. $8 \mathrm{a})$ to $\mathrm{SI}=$ $18^{\circ}(\delta /$ Din $=0.332$, Fig. $8 \mathrm{~b})$. In certain conditions the number of vortex pairs may be important as evaluated by the SP metric. In this case, although the thicker boundary layer increases the peak SI, there is not a significant change in the maximum SP. Although there are changes in the peak SI distortion, Profile A at $\theta=0^{\circ}$ shows a similar tendency towards the tri-modal swirl characteristic (bulk - twin - bulk swirl, Fig. $8 \mathrm{f}$ ) of the reference inlet condition $(\delta / \mathrm{Din}=$ 0.04 , Fig. 8e). The only minor difference is that the SP-SD and SI-SP maps exhibits a slightly more pronounced tendency towards twin swirl patterns $(\mathrm{SP}=1.0)$.

When Profile A $(\delta /$ Din $=0.332)$ is oriented at $\theta=45^{\circ}$, the SP-SD distribution shows a pronounced tendency towards positive offset and bulk swirl topology $(0.5<\mathrm{SP}<1,0<\mathrm{SD}<1$, Fig. $8 \mathrm{~g})$ in comparison with the reference inlet case $\left(\delta / \mathrm{Din}=0.04\right.$, Fig. 8e). This behavior becomes more evident for the $\theta=90^{\circ}$ orientation (Fig. $8 \mathrm{~h}$ ), whereby the flow is biased to positive bulk swirl $(\mathrm{SD}=1)$ and there is no longer evidence of negative bulk swirl events $(\mathrm{SD}=$ -1). Although the azimuthal orientation has a significant impact on the SP-SD distributions, the effect on the swirl intensity is much less. For example, relative to the $\theta=0^{\circ}$ configuration, there is a slight reduction in maximum SI from $18.5^{\circ}$ to about $17.5^{\circ}$ and $16.0^{\circ}$ for $\theta=45^{\circ}$ and $90^{\circ}$, respectively. The value of SI for the most likely events is broadly unaffected at $\mathrm{SI} \approx 10^{\circ}$.

The effects of the thicker inlet boundary layer Profile B $(\delta / \mathrm{Din}=0.572)$ on the j-PDF maps for SP-SD and SI-SP is similar, but more augmented, to those for the thinner Profile A $(\delta / \mathrm{Din}=0.332)$. For example, the primary effect of an increase of azimuthal angle in generating an asymmetric biased SP-SD is highly significant for Profile B (Fig. 9). For the configuration of Profile B with $\theta=90^{\circ}$ the j-PDF distribution shows that the flow is mostly dominated by the characteristic of a bulk positive swirl distribution (Fig. 9d). Furthermore, the SP-SD distribution shows a notable reduction in the scatter of events which is consistent with the overall reduction in flow unsteadiness with an increase in $\theta$ (Fig. $9 \mathrm{~d}, \mathrm{~h}$ ). Relative to the baseline configuration $(\delta / \mathrm{Din}=0.04)$ the thicker BL for Profile B modestly increases the most likely SI level from $7^{\circ}$ to $9.5^{\circ}$. This is similar to the effect of the thinner Profile A. As $\theta$ increases from $0^{\circ}$ this SI increases from about $9^{\circ}$ to $13^{\circ}$ for both $\theta=45^{\circ}$ and $90^{\circ}$ (Fig. 9c, d). Although the flow unsteadiness reduces significantly with $\theta$, the maximum levels of SI increase slightly from $17^{\circ}\left(\delta / \operatorname{Din}=0.572, \theta=0^{\circ}\right)$ to $21^{\circ}$ and $23^{\circ}$ for $\theta$ $=45^{\circ}$ and $90^{\circ}$, respectively. Overall, the effect the thickness of the inlet boundary layer is relatively modest in terms of the SP, SD and SI metrics for $\theta=0^{\circ}$. In contrast, these metrics are notably sensitive to the azimuthal position $\theta$ and these effects are also more accentuated for the thicker inlet boundary layer. 


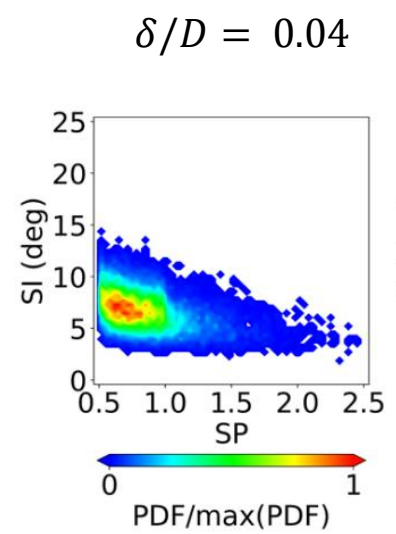

a)

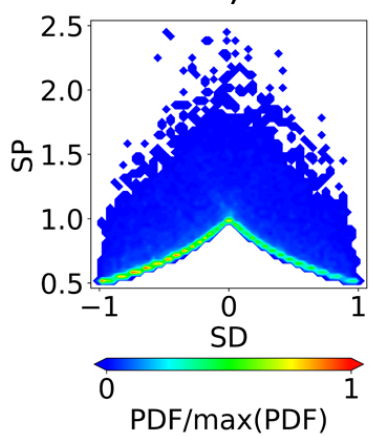

e)

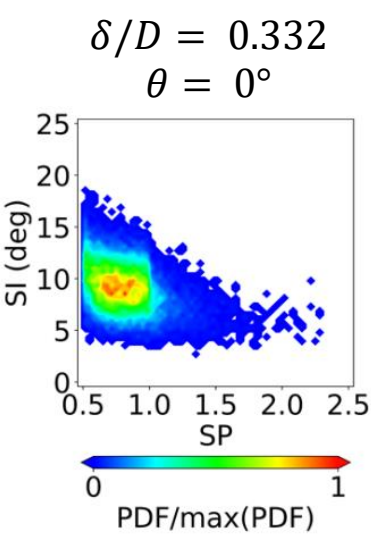

b)

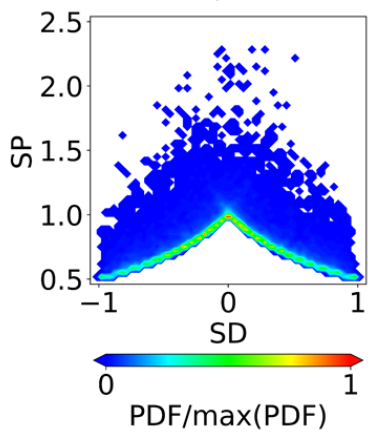

f)

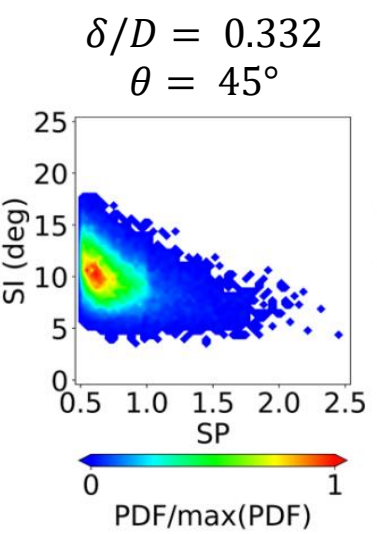

c)

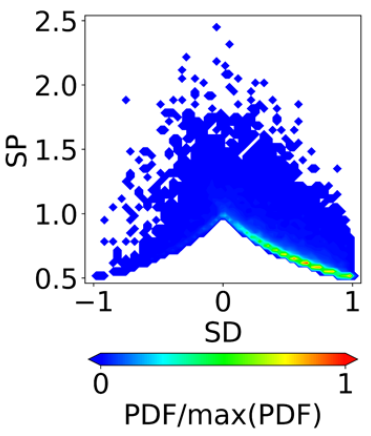

g)

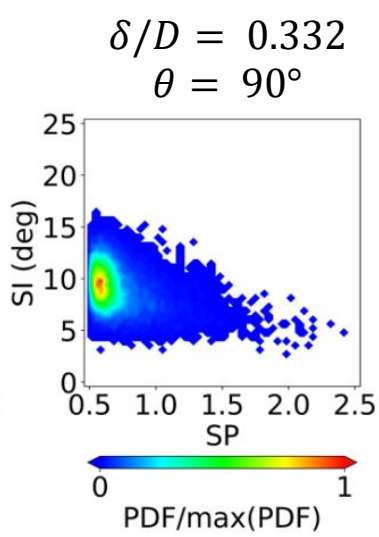

d)

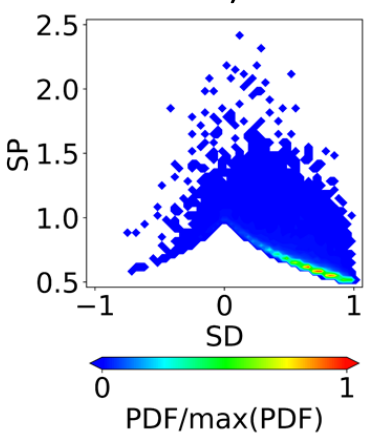

h)

Fig. 8: SP-SD and SI-SD j-PDF maps at the AIP for different intake operation: uniform inlet condition and Profile $A\left(\delta / D_{\text {in }}=0.332\right)$ at $0-45-90^{\circ}$ at $r / R_{\text {AIP }}=0.8$. 


\section{$\delta / D=0.04$}

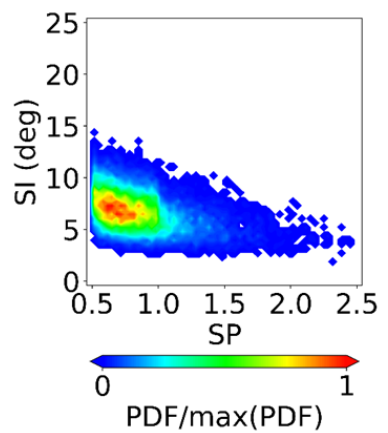

a)

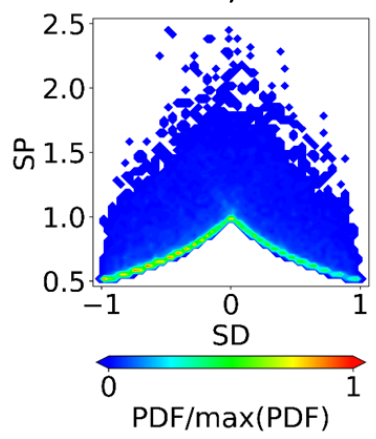

e)

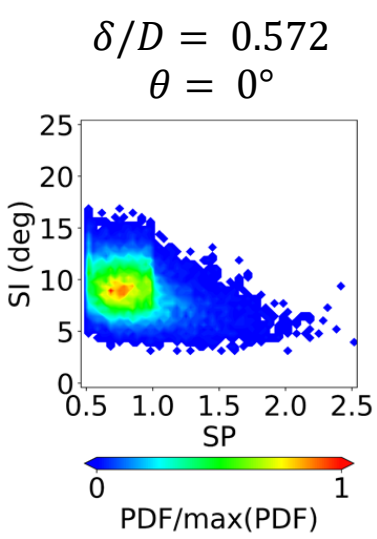

b)

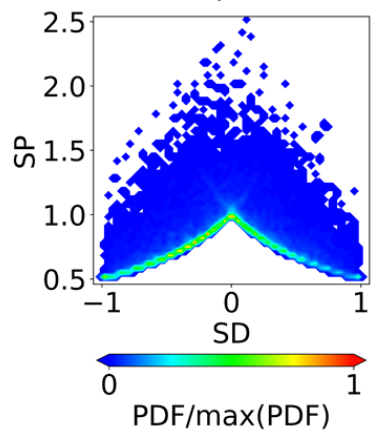

f)

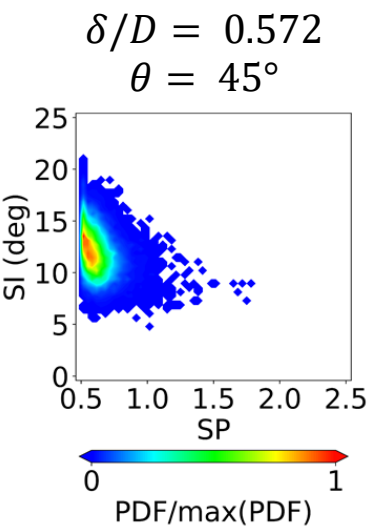

c)

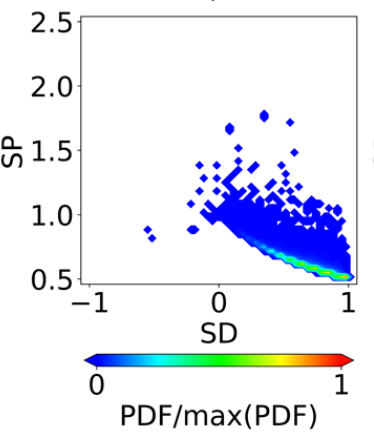

g)

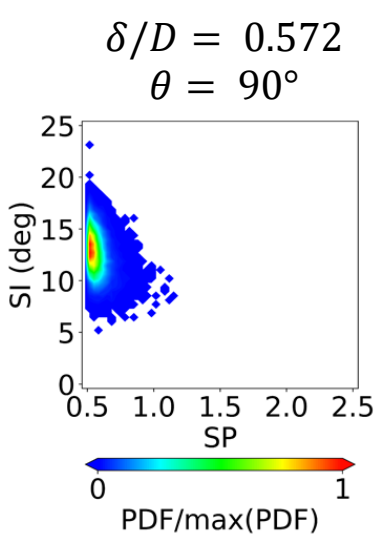

d)

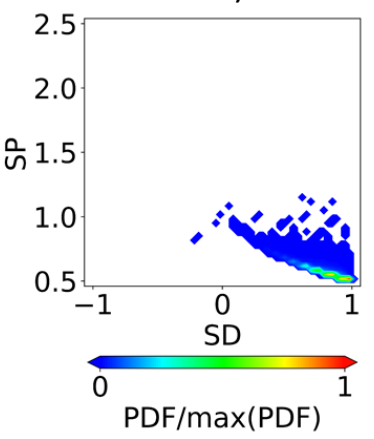

h)

Fig. 9: SP-SD and SI-SD j-PDF maps at the AIP for different intake operation: uniform inlet condition and Profile $B(\delta / \operatorname{Din}=0.572)$ at $0-45-90^{\circ}$ at $r / R_{A I P}=0.8$.

\section{Spectral analysis}

A spectral analysis was performed to determine the impact of the non-uniform inlet profiles on the AIP velocity frequency characteristics. The spectral analysis of the swirl angle distributions is used to provide band-pass spectra with a resolution of $\Delta S t=0.2$. For the reference case $(\delta / \mathrm{Din}=0.04)$, the main unsteadiness of the swirl distortion is between $\mathrm{St}=0.4-0.6$ (Fig. 10). This corresponds to the first switching mode ( $\mathrm{FSM}, \mathrm{St}=0.42$ ), reported by Gil-Prieto et al. [28] for the same S-duct geometry (high offset, $\mathrm{H} / \mathrm{L}=0.49$ ). This switching mode is mainly associated with the oscillation of the flow as it changes from bulk swirl $(\mathrm{SP}=0.5, \mathrm{SD}= \pm 1)$ to swirl pair $(\mathrm{SP}=1, \mathrm{SD}=0)$ distributions. In contrast, the contributions in the higher frequency bands correspond to the first vertical mode [28] (FVM, St $=0.6$ $1.0)$. Relative to the datum inlet condition $(\delta / \mathrm{Din}=0.04)$ the effect of the thicker inlet boundary layer for Profile $\mathrm{A}$ $\left(\delta / \operatorname{Din}=0.332, \theta=0^{\circ}\right)$ is to reduce the frequency of the main unsteady swirl distortion from $\mathrm{St}=0.4-0.6$ (baseline case $-\delta /$ Din $=0.04$, Fig. 10a) to $\mathrm{St}=0.2-0.4$ (Fig. 10b). There is also slight increase in the range of unsteady swirl with notable content still across the range $\mathrm{St}=0.2-0.6$. The main impact of increasing $\theta$ from $0^{\circ}$ to $45^{\circ}$ is to increase the frequency range of the main unsteadiness from $\mathrm{St}=0.2-0.4$ to $\mathrm{St}=0.4-0.6$ (Fig. 10c). The overall level of unsteadiness is reduced and confined to a narrower band. This effect of $\theta$ is further emphasized for $\theta=90^{\circ}$ where the primary unsteadiness arises at $\mathrm{St}=0.6-0.8$ (Fig. 10d). In agreement with the changes to the primary flow distributions and the biasing towards a dominant asymmetric flow (Fig. 7) the distribution of the unsteadiness is also more asymmetric. As the overall levels of unsteadiness reduce with $\theta$ (Fig. 7) the spectral signature is less narrow and more evenly distributed across the range $\mathrm{St}=0.4-1.0$. In general the effect of the thicker boundary layer (Profile $\mathrm{B}, \delta / \mathrm{Din}=0.572$, $\theta=0^{\circ}$ ) is similar to profile $\mathrm{A}$ with a reduction in the domain frequencies band by about $\mathrm{St}=0.2$ (Fig. 11b). The impact of $\theta$ for Profile B is also similar to Profile A. There is a minor difference for the impact of $\theta=0^{\circ}$ where the swirl unsteadiness is more narrow band at $\mathrm{St}=0.6-0.8$. This is consistent with the significant flow mode locking for this configuration where the j-PDF maps show less scatter (Fig. 9h). 
For a typical propulsion system, the critical range of frequencies to which a fan is likely to respond was previously identified to be between 1 engine order and the passing time of a 5-blades sector [8]. The high incidence angles could also excite the first resonant frequency of the compressor rotor blades, which is typically St $=0.7$ for model scale compressor [36]. Thus, considering a representative transonic rotor [37], it can be stated that the engine may respond to instabilities with a frequency range between $\mathrm{St}=0.6$ (1 engine order) and $\mathrm{St}=2.6$ (passing time of a 5-blades sector). The distortion events that are shown within this work are therefore in the frequency range of interest for the engine instabilities. However, the lower the frequency of the disturbances, the higher is the magnitude required to trigger stall inception [38]. Therefore, it is theorized that the shift towards a lower frequency bands observed with Profile A and Profile B at $\theta=0^{\circ}$ may be beneficial for the engine stability. However, the frequency range of the swirl angle unsteadiness increases for the cases of ingestion of Profile $\mathrm{A}$ and $\mathrm{B}$ at $\theta=90^{\circ}$. Therefore the operation of the intake with these conditions may affect the operability margin of the engine.

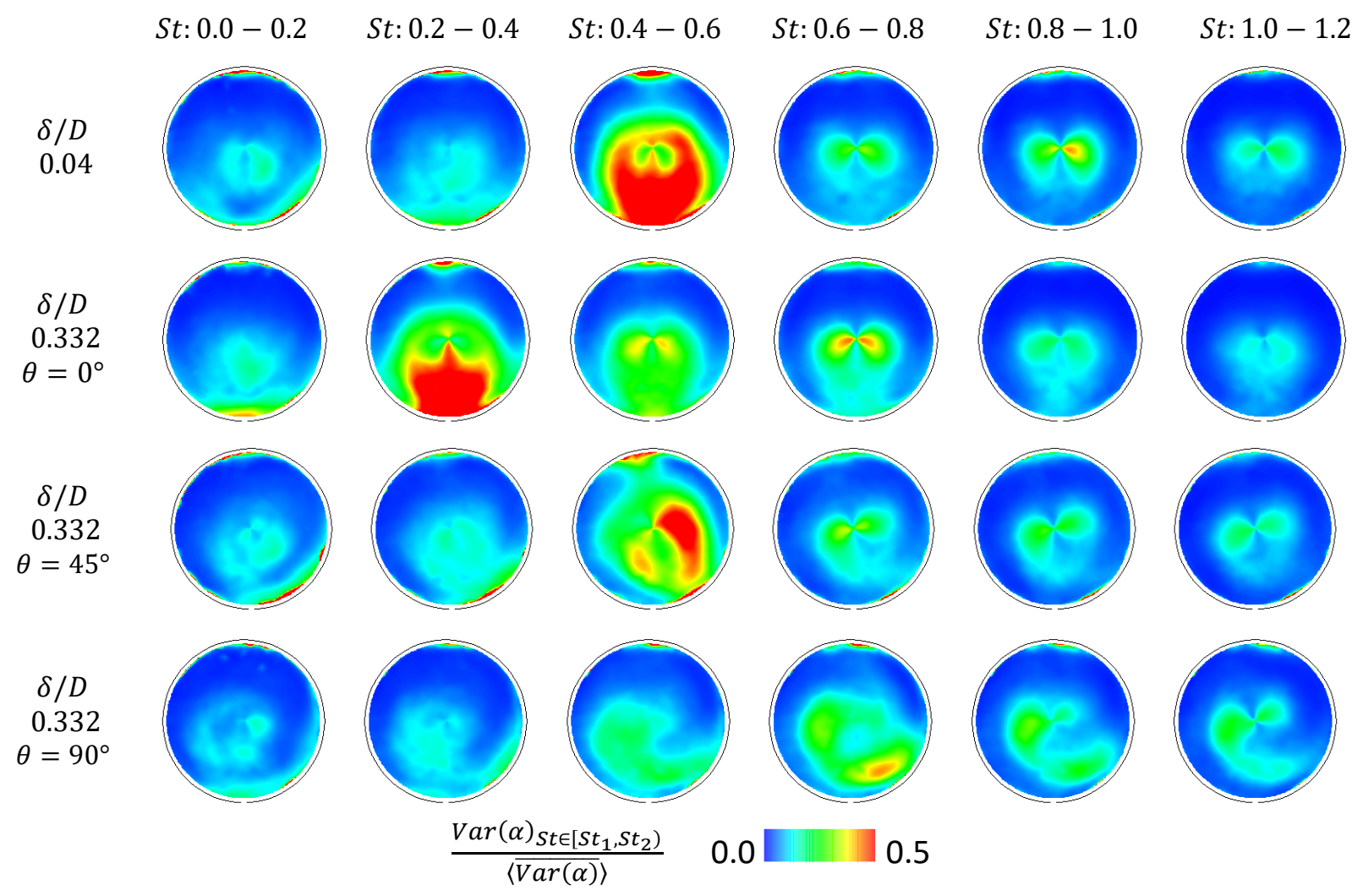

Fig. 10: Banded spectra of $\Delta S t=0.2$ for swirl angle at the AIP for nominal and Profile A inlet conditions. 


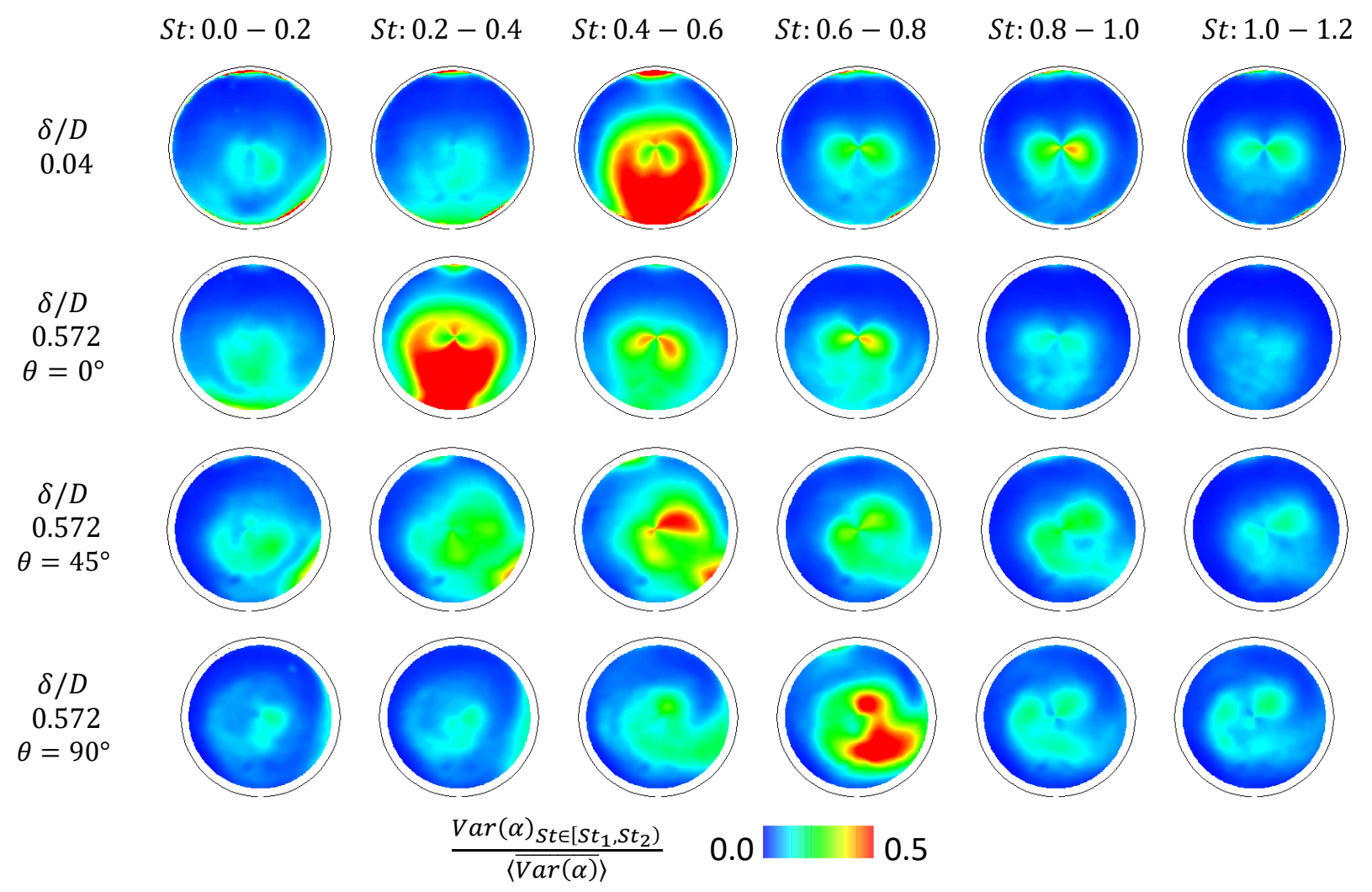

a)

b)

c)

d)

Fig. 11: Banded spectra of $\Delta S t=0.2$ for swirl angle at the AIP for nominal and Profile B inlet conditions.

\section{Conclusion}

This work demonstrates the impact of different inlet boundary thickness on the unsteady distortion characteristics of an S-shaped aero-engine intake. The inlet boundary layers upstream of the S-duct inlet were generated synthetically using 3D-printed honeycomb screens in which the variable solidity of the cells generated a total pressure profile. Two different inlet boundary layers with $\delta / \operatorname{Din}=0.332$ and $\delta / \operatorname{Din}=0.572$ were used to determine the influence of the boundary layer height onto the flow distortion at the outlet of the S-duct intake. The thicker profiles intensified the unsteadiness of the out-of-plane and swirl angle in comparison with the baseline inlet condition $\delta / \mathrm{Din}=0.04$. Although the overall flow topology was maintained even with thicker boundary layers, the maximum time-averaged swirl angles increased by up to $60 \%$. The phenomenon is caused by the augmented downward pitching flow that favors the strengthening of the typical S-duct secondary flows.

The S-duct secondary flows were influenced also by the azimuthal orientation of the inlet boundary layer. For orientations were the inlet vorticity was not aligned with the duct centerline, a notable growth and predominance of one of the two Dean vortices was observed. This was attributed to the effect of the asymmetry on the separated centerline shear layer and the additional downward pitching flow that strengthens the dominant vortex. In addition, asymmetric positions of the inlet boundary layer increased the maximum time-averaged swirl angle as well as reduced significantly the swirl unsteadiness.

The evaluation of the swirl distortion descriptor enhanced the analysis of the unsteady modes and most probable swirl patterns at the AIP. The thick boundary layers did not overcome the tri-modal switching mode observed with the reference inlet boundary layer but, however, the swirl intensity of thick boundary layers was up to $30 \%$ higher than the reference case. On the other hand, the probability distributions of the swirl events was more sensitive to changes in the azimuthal orientation of the inlet profiles. A strong bias to positive bulk swirl was observed when the boundary layers approached the S-duct inlet rotated by $90^{\circ}$. Interestingly, the associated peak swirl intensity increased by up to 6 degrees relative to the configurations in which the boundary layer is aligned with the S-duct centerline.

The introduction of a thick inlet boundary layer decreased the main frequency range of the swirl events from $\mathrm{St}=$ $0.4-0.6$ to $\mathrm{St}=0.2-0.4$. This was theorized to be beneficial from the point of view of the intake-engine compatibility, because the frequency of the swirl distortion shifted to the lower end of the critical range of frequencies in which a 
disturbance can cause instability to the propulsion system. However, the inlet profiles approaching at $90^{\circ}$ recorded a main frequency band of unsteadiness of $\mathrm{St}=0.6-0.8$. This is considered non-optimum for mechanical blading perspective, since it could excite the first resonant frequency of the rotor which is set generally at $\mathrm{St}=0.7$.

Overall, this works gives guidelines for the correct integration between the intake and the engine across the range of potential aircraft operating conditions. The aim is to facilitate the work of aero-engine designers to understand the unsteady swirl angles at the S-duct intake AIP and to facilitate the design of compressor geometries that can suppress or tolerate the flow distortion of complex intakes.

\section{Acknowledgments}

Mr. Migliorini is partially funded by UK Engineering and Physical Sciences Research Council. Due to commercial confidentiality agreements the supporting data is not available.

\section{References}

[1] Epstein, A. H., "Aeropropulsion for Commercial Aviation in the Twenty-First Century and Research Directions Needed," AIAA Journal, vol. 52, 2014, pp. 901-911, doi: 10.2514/1.J052713.

[2] ACARE, "Flightpath 2050," 2011.

[3] Hall, D. K., Huang, A. C., Uranga, A., Greitzer, E. M., Drela, M., and Sato, S., "Boundary Layer Ingestion Propulsion Benefit for Transport Aircraft," Journal of Propulsion and Power, vol. 33, Mar. 2017, pp. 1118-1129, doi: 10.2514/1.B36321.

[4] Drela, M., "Development of the D8 Transport Configuration," 29th AIAA Applied Aerodynamics Conference, Honolulu, AIAA, 2011.

[5] Wiart, L., Atinault, O., Boniface, J.-C., and Barrier, R., "Aeropropulsive Performance Analysis of the NOVA Configurations," 30th Congress of the International Council of the Aeronautical Sciences, Daejeon, ICAS, 2016.

[6] Bijewitz, J., Hornung, M., Isikveren, A. T., and Seitz, A., "Multi-disciplinary design investigation of propulsive fuselage aircraft concepts," Aircraft Engineering and Aerospace Technology, vol. 88, Mar. 2016, pp. 257-267, doi: 10.1108/AEAT-02-2015-0053.

[7] Uranga, A., Drela, M., Greitzer, E., Titchener, N., Lieu, M., Siu, N., Huang, A., M. Gatlin, G., and Hannon, J., "Preliminary Experimental Assessment of the Boundary Layer Ingestion Benefit for the D8 Aircraft," 52nd Aerospace Sciences Meeting, National Harbor, Maryland, 2014, p. 25.

[8] Cousins, W. T., "History, philosophy, physics, and future directions of aircraft propulsion system / inlet integration," Proceedings of the ASME Turbo Expo, Vienna, ASME, 2004, pp. 305-320.

[9] Melick, H. C., J., “Analysis of inlet flow distortion and turbulence effects on compressor stability,” NASA-CR-114577, TR-2-57110/3R-3071, Dallas, 1973.

[10] Awatef, H., and Keith, N., "Inlet distortion considerations for high cycle fatigue in gas turbine engine," AIAA/ASME/SAE/ASEE Joint Propulsion Conference and Exhibit 33rd ,Seattle WA, July 6-9 1997, Seattle, AIAA, 1997.

[11] Kammerer, A., and S. Abhari, R., "Experimental Study on Impeller Blade Vibration During Resonance-Part I: Blade Vibration Due to Inlet Flow Distortion," Journal of Engineering for Gas Turbines and Power, vol. 131, Dec. 2008, p. 11, doi: $10.1115 / 1.2968869$.

[12] Im, H., and Zha, G., "Investigation of Flow Instability Mechanism Causing Compressor Rotor-Blade Nonsynchronous Vibration,” AIAA Journal, vol. 52, Jul. 2014, pp. 2019-2031, doi: 10.2514/1.J052781.

[13] Bakhle, M., Reddy, T., Herrick, G., Shabbir, A., and Florea, R., “Aeromechanics Analysis of a Boundary Layer Ingesting Fan," 48th AIAA/ASME/SAE/ASEE Joint Propulsion Conference \& Exhibit, Atlanta, AIAA, 2012.

[14] Giuliani, J. E., and Chen, J.-P., "Fan Response to Boundary-Layer Ingesting Inlet Distortions," AIAA Journal, vol. 54, 2016, pp. 3232-3243, doi: 10.2514/1.J054762.

[15] van Dam, E., "Inlet Distortion Characterization of the Boundary Layer Ingesting D8 Aircraft,” Ph. D. dissertation, Faculty of Aerospace Engineering, University of Technology, NL, Delft, 2015.

[16] Reynolds, A. J., "Flow Deflection by Gauze Screens,” Journal of Mechanical Engineering Science, vol. 11, Jun. 1969, pp. 290-294, doi: 10.1243/JMES_JOUR_1969_011_036_02.

[17] Pinker, R. A., and Herbert, M. V. ., "Pressure loss associated with compressible flow through square-mesh wire gauzes," Journal of Mechanical Engineering Science, vol. 9, 1967, pp. 11-23, doi: 10.1243/JMES_JOUR_1967_009_004_02.

[18] Laws, E. M., and Livesey, J. L., "Flow Through Screens," Annual Review of Fluid Mechanics, vol. 10, 1978, pp. 247- 
266, doi: 10.1146/annurev.fl.10.010178.001335.

[19] Gunn, E. J., and Hall, C. A., “Aerodynamics of Boundary Layer Ingesting Fans,” ASME Turbo Expo 2014: Turbine Technical Conference and Exposition, Volume 1A: Aircraft Engine; Fans and Blowers, Düsseldorf, ASME, 2014.

[20] Guimarães, T., Lowe, K. T., and O’Brien, W. F., "StreamVane Turbofan Inlet Swirl Distortion Generator: Mean Flow and Turbulence Structure," Journal of Propulsion and Power, vol. 34, Oct. 2017, pp. 340-353, doi: 10.2514/1.B36422.

[21] Schneck, W., Ferrar, A., Bailey, J., Hoopes, K., and O’Brien, W., "Improved Prediction Method for the Design of HighResolution Total Pressure Distortion Screens," 51 st AIAA Aerospace Sciences Meeting including the New Horizons Forum and Aerospace Exposition, Grapevine (Dallas/Ft. Worth Region), AIAA, 2013.

[22] Taylor, J. V., "Complete flow conditioning gauzes," The 24th Symposium on Measuring Techniques in Turbomachinery. Transonic and Supersonic Flow in Cascades and Turbomachines, Prague, Czech Republic, 2018.

[23] Gil-Prieto, D., MacManus, D. G., Zachos, P. K., Tanguy, G., and Menzies, K. R., "Convoluted Intake Distortion Measurements Using Stereo Particle Image Velocimetry," AIAA Journal, vol. 55, 2017, pp. 1878-1892, doi: 10.2514/1.J055467.

[24] Gil-Prieto, D., Macmanus, D. G., Zachos, P. K., Tanguy, G., Wilson, F., and Chiereghin, N., "Dynamic Flow Distortion Investigation in an S-duct using DDES and SPIV data," 34th AIAA Applied Aerodynamics Conference, Washington DC, AIAA, 2016.

[25] Zachos, P. K., MacManus, D. G., Prieto, D. G., and Chiereghin, N., "Flow Distortion Measurements in Convoluted Aeroengine Intakes,” AIAA Journal, vol. 54, 2016, pp. 2819-2832, doi: 10.2514/1.J054904.

[26] Garnier, E., "Flow Control by Pulsed Jet in a Curved S-Duct: A Spectral Analysis," AIAA Journal, vol. 53, 2015, pp. 2813-2827, doi: 10.2514/1.J053422.

[27] Gil-Prieto, D., MacManus, D. G., Zachos, P. K., Tanguy, G., Wilson, F., and Chiereghin, N., "Delayed Detached-Eddy Simulation and Particle Image Velocimetry Investigation of S-Duct Flow Distortion,” AIAA Journal, vol. 55, 2017, pp. 1893-1908, doi: 10.2514/1.J055468.

[28] Gil-Prieto, D., Zachos, P. K., MacManus, D. G., and McLelland, G., "Unsteady characteristics of S-duct intake flow distortion," Aerospace Science and Technology, vol. 84, 2019, pp. 938-952, doi: https://doi.org/10.1016/j.ast.2018.10.020.

[29] Raffel, M., Willert, C. E., Wereley, S. T., Kompenhans, J., Willert, S., Wereley, S. T., and Kompenhans, J., "Particle Image Velocimetry: A Practical Guide," Berlin, 2007.

[30] Guimaraes Bucalo, T., Lowe, K. T., and O'Brien, W. F., "An overview of recent results using the StreamVane method for generating tailored swirl distortion in jet engine research," 54th AIAA Aerospace Sciences Meeting, San Diego, AIAA, 2016.

[31] SAE, “A Methodology for Assessing Inlet Swirl Distortion,” 2007.

[32] Lee, D. T., and Schachter, B. J., "Two algorithms for constructing a Delaunay triangulation," International Journal of Computer \& Information Sciences, vol. 9, 1980, pp. 219-242, doi: 10.1007/BF00977785.

[33] D. Welch, P., "The Use of Fast Fourier Transform for the Estimation of Power Spectra: A Method Based on Time Averaging Over Short, Modified Periodograms," IEEE Transactions on Audio and Electroacoustics, 1967, pp. 70-73.

[34] Dean, W. R., "Note on the motion of fluid in a curved pipe," The London, Edinburgh, and Dublin Philosophical Magazine and Journal of Science, vol. 4, 1927, pp. 208-223, doi: 10.1080/14786440708564324.

[35] MacManus, D. G., Chiereghin, N., Prieto, D. G., and Zachos, P., "Complex Aeroengine Intake Ducts and Dynamic Distortion," AIAA Journal, vol. 55, 2017, pp. 2395-2409, doi: 10.2514/1.J054905.

[36] Provenza, A. J., Duffy, K. P., and Bakhle, M. A., "Aeromechanical Response of a Distortion Tolerant Boundary Layer Ingesting Fan,” Journal of Engineering for Gas Turbines and Power, vol. 141, 2018, doi: 10.1115/1.4040739.

[37] Strazisar, A. J., and Powell, J. A., "Laser anemometer measurements in a transonic axial flow compressor rotor," NASA TP-2879, 1989.

[38] Page, J. H., Hield, P., and Tucker, P. G., "Effect of Inlet Distortion Features on Transonic Fan Rotor Stall," Journal of Turbomachinery, vol. 140, Jun. 2018, pp. 71008-71011, doi: 10.1115/1.4040030. 


\section{Correction: [The impact of inlet boundary layer thickness on the unsteady aerodynamics of S-duct intakes]}

Author(s) Name: Matteo Migliorini(1); Pavlos Zachos(1); David MacManus(1)

Author(s) Affiliations: 1. Cranfield University, Bedford, United Kingdom.

\section{Correction Notice:}

1. In Figure 5, the legend labels are not correct. Please refer to the "corrected" labels below:

\begin{tabular}{|c|c|}
\hline Old version & Corrected \\
\hline$\langle\bar{w}\rangle / W_{\text {ref }}$ & $\langle w\rangle /\langle\bar{w}\rangle$ \\
\hline$s t d(w) / W_{\text {ref }}$ & $s t d(w) /\langle\bar{w}\rangle$ \\
\hline$\langle\bar{\alpha}\rangle$ & $\langle\alpha\rangle$ \\
\hline
\end{tabular}

2. In the Nomenclature list, the following indication is missing:

Var = variance 
2019-09-16

The impact of inlet boundary layer

thickness on the unsteady

aerodynamics of S-duct intakes

\author{
Migliorini, Matteo
}

AIAA

Migliorini M, Zachos PK, MacManus DG. (2019) The impact of inlet boundary layer thickness on the unsteady aerodynamics of S-duct intakes. In: Proceedings of the AIAA Propulsion and Energy 2019 Forum, 19-22 August 2019, Indianapolis, IN, USA. AIAA 2019-4202 Including corrections. https://doi.org/10.2514/6.2019-4202

Downloaded from Cranfield Library Services E-Repository 